\title{
A farm-scale pilot plant for biohydrogen and biomethane production by two-stage fermentation
}

\author{
R. Oberti, A. Tenca , F. Perazzolo, E. Riva, A. Finzi, E. Naldi, G. Provolo, L. Bodria \\ DiSAA, Dipartimento di Scienze Agrarie e Ambientali, Università degli Studi di Milano, Milano, \\ Italy
}

\begin{abstract}
Hydrogen is considered one of the possible main energy carriers for the future, thanks to its unique environmental properties. Indeed, its energy content (120 MJ/kg) can be exploited virtually without emitting any exhaust in the atmosphere except for water. Renewable production of hydrogen can be obtained through common biological processes on which relies anaerobic digestion, a well-established technology in use at farm-scale for treating different biomass and residues.

Despite two-stage hydrogen and methane producing fermentation is a simple variant of the traditional anaerobic digestion, it is a relatively new approach mainly studied at laboratory scale. It is based on biomass fermentation in two separate, seuqential stages, each maintaining conditions optimized to promote specific bacterial consortia: in the first acidophilic reactorhydrogen is produced production, while volatile fatty acids-rich effluent is sent to the second reactor where traditional methane rich biogas production is accomplished.

A two-stage pilot-scale plant was designed, manufactured and installed at the experimental farm of the University of Milano and operated using a biomass mixture of livestock effluents mixed with sugar/starch-rich residues (rotten fruits and potatoes and expired fruit juices), afeedstock mixture based on waste biomasses directly available in the rural area where plant is installed.

The hydrogenic and the methanogenic reactors, both CSTR type, had a total volume of $0.7 \mathrm{~m} 3$ and $3.8 \mathrm{~m} 3$ respectively, and were operated in thermophilic conditions $\left(55 \square 2{ }^{\circ} \mathrm{C}\right)$ without any external $\mathrm{pH}$ control, and were fully automated.

After a brief description of the requirements of the system, this con-
\end{abstract}

Correspondence: Roberto Oberti, DiSAA Dipartimento di Scienze Agrarie e Ambientali, Università degli Studi di Milano, via Celoria 2, Milano (Italy). E-mail: roberto.oberti@unimi.it

Key words: biohydrogen, two-stage anaerobic digestion, farm-scale pilot plant.

Acknowledgments: the authors gratefully acknowledge the support of Regione Lombardia - DG Agricoltura to this research, through the projects AGRIDEN/1181 and BIOGESTECA 15083/RCC.

CCopyright R. Oberti et al., 2013

Licensee PAGEPress, Italy

Journal of Agricultural Engineering 2013; XLIV(s2):e115

doi:10.4081/jae.2013.s2.e115

This article is distributed under the terms of the Creative Commons Attribution Noncommercial License (by-nc 3.0) which permits any noncommercial use, distribution, and reproduction in any medium, provided the original author(s) and source are credited. tribution gives a detailed description of its components and of engineering solutions to the problems encountered during the plant realization and start-up.

The paper also discusses the results obtained in a first experimental run which lead to production in the range of previous laboratory results, with a typical hydrogen and methane specific productivity of 2.2 and $0.5 \mathrm{Nm} 3 / \mathrm{m} 3$ reactor per day, in the first and second stage of the plant respectively.

At our best knowledge, this plant is one of the very first prototypes producing biohydrogen at farm scale, and it represents a distributed, small scale demonstration to obtain hydrogen from renewable waste-sources.

\section{Introduction}

Hydrogen is considered one of the main possible energy carriers in future, thanks to its energetic and environmental unique properties: indeed, its energy content $(120 \mathrm{MJ} / \mathrm{kg})$ is three times higher than liquid fuels -but with a much lower volumetric density- and it can be converted to energy virtually without any exhaust emissions in the atmosphere except for water. In substitution of current fossil-fuel based technologies, renewable production of hydrogen from dark fermentation of biomasses could provide all the potential benefits of hydrogen energy production, especially if obtained by wastewaters or residues digestion.

Biohydrogen production has been demonstrated for a number of organic substrates especially rich in carbohydrates (starch, sugar beets, potatoes processing wastewaters, cheese whey, brewery waste, etc.) with yields typically ranging between 50 and $150 \mathrm{Ndm}^{3}{ }_{\mathrm{H} 2} \mathrm{~g}^{-1} \mathrm{vs}$, depending on the biodegradability and complexity of the substrate. However, the maximal yield of the process is low $\left(4 \mathrm{~mol}_{\mathrm{H} 2} / \mathrm{mol}_{\text {glucose }}\right)$ with residual organic matter left unexploited in the process effluent, highly rich in volatile fatty acids (VFAs).

Therefore, recently some studies proposed the coupling of fermentative hydrogen production with traditional anaerobic digestion (AD) process, able to fully exploit the VFAs by converting them to methane and thus increasing the total energy efficiency (Liu et al., 2006; Ueno et al., 2007). Indeed, AD technology is already a well-established bioprocess technology, extensively applied at real-scale, especially in the agricultural sector. In 2010 the $20 \%$ of Italian biogas production from biomasses relied on agricultural and livestock residues digestion, which means an opportunity to integrate farmers' income and a contribution to reduce the dependency on fossil energy sources and to progress toward mitigation of emissions in atmosphere especially in areas with high concentration of livestock production such as in specialized districts of Northern Italy.

The transformation of the traditional single-stage $\mathrm{AD}$ process in two distinct stages, respectively producing biohydrogen and methane-rich biogases, may therefore represent a feasible and advantageous evolu- 
tion of this well established technology, quite promising from a perspectiveof energy and environmental efficiency. Indeed, every single stage may be operated in specifically optimal conditions, likely leading to a larger overall reaction rate and biogas yield and to higher organic matter removal efficiencies, thus improving the reduction of the waste density levels at farm scale.

Furthermore, hydrogen can be processed and upgraded to be suitably employed in end-use zero- emissions technologies like fuel cells, or mixed with the methane produced by the second stage and used in high-effiency low-emission combustion engines (Akansu et al., 2004, Ma et al., 2010) as the new homogeneous charge compression ignition (HCCI) engines (Gomes Antunes et al., 2008).

At laboratory scale, studies on two-stage process mainly addressed possible designs and reactor configurations, operative parameters optimization ( $\mathrm{pH}$, temperature, stirring rate), biogas/biohydrogen production maximization, and microorganisms interactions/association within the reactors.

Concerning the scaling up of such a system, just a couple pilot-scale studies were reported at our best knowledge (Cavinato et al., 2011; Lee \& Chung, 2010; Ueno et al.,2007; Wang \& Zhao, 2009). These plants were operated with heterogeneously concentrated $\left(50-200 \mathrm{~g}_{\mathrm{V}} / \mathrm{kg}\right)$ wet biomasses, mainly carbohydrate-rich (food wastes, pulverized garbage and shredded paper wastes, separately collected organic fraction of municipal waste), with average hydrogen yields of $60 \mathrm{Ndm}^{3}{ }_{\mathrm{H} 2} / \mathrm{kg}_{\mathrm{VS}}$, corresponding to specific volumetric production in the range of $2-5$ $\mathrm{Nm}^{3}{ }_{\mathrm{H} 2} / \mathrm{m}^{3}$ reactor $\mathrm{d}$, at short HRT typically of 1-3 days. The average methane yield from the second CSTR stage ranged between 500 and $650 \mathrm{Ndm}^{3} \mathrm{CH}_{4} / \mathrm{kg}_{\mathrm{Vs}}$, with HRT variation from 12 to 40 days (Cavinato et al. 2011; Wang \& Zhao, 2009).

This paper describes the two-stage pilot-scale plant which was designed, manufactured and installed at "Cascina Marianna" (Landriano, Italy), the experimental farm of the University of Milano. The plant represent the first example of facility for simultaneous biohydrogen and biomethane production. It is based on simple, low-cost and readily applicable technologies, with a general design conceived for farm scale applications. Within this same framework, the reactors were inoculated exploiting mixed culture from natural sources, and fed with a mixture of waste biomasses (fruit and vegetable wastes and livestock residues) directly available in the specific rural area where the plant is installed. Engineering solutions to the problems encountered during the plant realization and start-up are hereby discussed, together with preliminary experimental plant performances.

\section{Materials and methods}

\section{Process scheme and pilot-scale plant design}

The pilot plant system design combines three cylindrical, heated, continuously stirred tank reactors (CSTRs) made by PVC, one of the most adopted biogas-plant technology for wet biomasses digestion.

With reference to figure 1, the plant operation can be summarized as follows: the feeding substrate mixture is pumped to a first hydrogenic reactor (Fig $1 ; 3$ ) where the organic matter is hydrolyzed and biologically acidified, producing gaseous hydrogen and carbon dioxide and a effluent digestate rich in VFAs. The digestate is then sent to the second stage of the process, occurring in two identical reactors (Fig 1; 4a and 1; 4b), which together act as a single methanogenic stage, producing a methane-rich biogas and effluent digestate. The end digestate is then stored to be used for fertilizer spreading by the farm.
The two biogases produced by each stage are separately collected in gas bags storage (Fig $1 ; 6 \mathrm{a}$ and $1 ; 6 \mathrm{~b}$ ) above the reactors.

After preparation by shredding in a biotriturator (Fig $1 ; 1$ ), the substrate biomass is blended with an appropriate amount of manure. The resulting feedstock is then stored in a $1.2 \mathrm{~m}^{3}$ pre-feeding refrigerated tank (Fig $1 ; 2$ ) with a double-walled stainless-steel shell and agitator blades keeping the feedstock at $4{ }^{\circ} \mathrm{C}$ and continuously gently mixed. This allows to have an operational autonomy of 3-5 days during experiments, while avoiding major pre-acidification of the substrate.

The hydrogenic reactor (Fig $1 ; 3)$ has a capacity of $0.7 \mathrm{~m}^{3}(1.2 \mathrm{~m}$ in height $\times 0.9 \mathrm{~m}$ in diameter), while the methanogenic stage occurs in a pair of identical larger reactors (Fig $1 ; 4 \mathrm{a}$ and $4 \mathrm{~b}$ ), with a total capacity of $3.8 \mathrm{~m}^{3}$, (two reactors $1.95 \mathrm{~m}$ in height $\mathrm{x} 1.1 \mathrm{~m}$ in diameter). The operative volumes of each reactor may be individually varied, and in this study they were set to $0.4 \mathrm{~m} 3$ for the first stage and to $3.2 \mathrm{~m}^{3}$ (1.6 $\mathrm{m}^{3}$ for each reactor) for the methanogenic stage, respectively, resulting in hydraulic retention times ratio of $1 / 8$ between the two stages of the process.

Each reactor is provided with a internal folding coil in order to maintain the temperature of the fermentative broth constantly at $55{ }^{\circ} \mathrm{C}$ through hot-water circulation, and with mechanical stirring system operated at $60 \mathrm{rpm}$ to keep the substrate homogenously in contact with microorganisms, the temperature uniformly distributed though the broth and to minimize the formation of scum at the surface or solids deposition on the bottom likely leading to blockages in the system.

In each reactor are installed different sensors (Fig 1;8) for continuous monitoring of the process as well as for automatic control (Fig 1;9) of the operation of the plant purposes. Pt-100 temperature sensors, pH electrodes and broth levels sensors are installed on the front side of the tank, together with ports designed for physical sampling of fermentative broth.

The biomass is handled to and from different points of the plant by the use of two impeller pumps (Fig. 1; 5a and 5b): loading and unloading of the hydrogenic reactor and methanogenic reactors, as well as transfer from first stage to the second, or recirculation of material if needed. All these configurations of the circuit can be obtained through adequate actuation of eight pneumatically activated valves directly controlled by the digital control system.

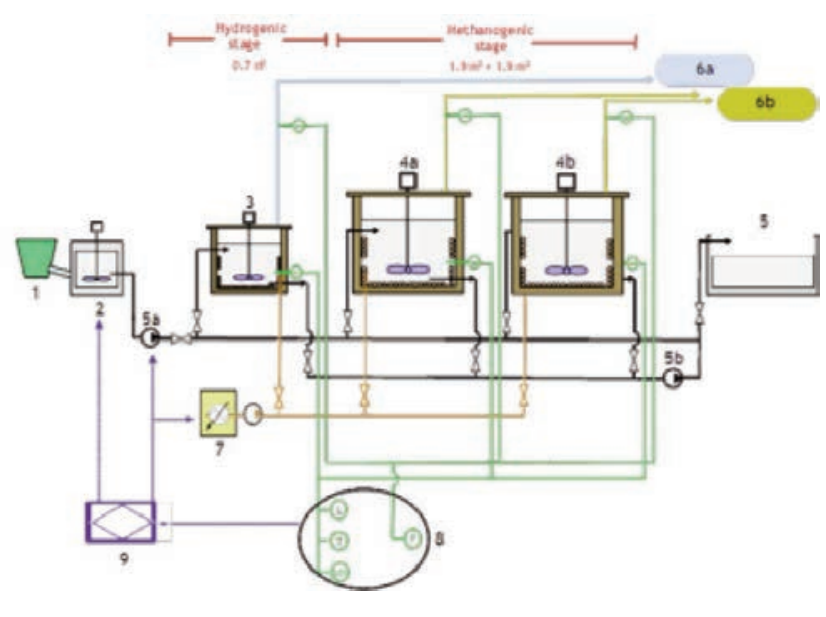

Figure 1. Schematic diagram of the two-stage pilot plant: 1) biotriturator for solid biomass shredding; 2) $1.2 \mathrm{~m}^{3}$ refrigerated pre-feeding storage; 3) $0.7 \mathrm{~m}^{3}$ hydrogenic reactor; $\left.4 \mathrm{a}-\mathrm{b}\right)$ pairs of $1.9 \mathrm{~m} 3 \mathrm{methanogenic} \mathrm{reactors;}$ 5a-b) impeller pumps for biomass handling; 6a-b) gas bags storage; 7) boiler for heating system; 8 ) temperature, $\mathrm{pH}$ and gas flow-rate sensors; 9) PC based digital control system. 


\section{Process monitoring and control}

Process parameters monitoring and automatic control of process operations rely on PC-based digital control system (DCS). The custom-made DCS monitors, records and displays on a user-interface the process data transmitted by the sensors. Volumetric biogas production from each reactor is continuously measured by three gas flow meters (LPN/S80 AL G 2.5 SACOFGAS, , Italy). The gas composition was measured once a day by manually taking a sample from the outlet biogas pipe and measuring it with a gas analyzer (ETG-3200L, ETG Risorse e Tecnologia, Italy). Beside data recording, the DCS activates or modulates the biomass flow in to the plant, the reactors' stirring and the hot water circulation for temperature control according to operator's setting.

During all the experiment the temperature was maintained at $55 \pm$ $2.5^{\circ} \mathrm{C}$ and mixing cycle was set to 2 minutes followed by a 30 seconds of settling stop in the first stage, while in the methanogenic stage the cycle was 1 minute of mixing followed by 1 minute of settling.Loading and unloading of organic substrate was managed on the basis of the two HRTs chosen, set to 2.5 and 20 days for the hydrogenic and methanogenic stage respectively.

The fermentative broths of each reactor were manually sampled four times along the steady state period of the experimental run described in section 3.2 , in order to chemically characterize the stages and their removal efficiencies through the measure of total and volatile solids (TS and VS) and of chemical oxygen demand (COD), according to Standard Methods (APHA, 1998).

\section{Feedstocks and inocula}

The feeding substrate was a mixture of livestock manure (LM: $65 \%$ $\mathrm{w} / \mathrm{w}$ ) and fruit and vegetable waste (FVW: $65 \% \mathrm{w} / \mathrm{w}$ ), according to the ratio indicated by previous lab-scale preliminary tests (Tenca et al., 2011). FVW consisted of a mixture of raw and rotten fruits and vegetables residues (mainly potatoes, zucchini and apples). The solid wastes were freshly shredded and mixed together with the fruit juices and the LM. The manure is an ideal co-substrate for FVW fermentation, being an abundant source of alkali and nutrients for cell growth and process $\mathrm{pH}$ buffering. LM was not filtered nor treated before feeding. No chemical reagents, buffers or other nutrients were added to the blend, whose TS, VS and pH were $58 \pm 4 \mathrm{~g} / \mathrm{kg}, 52 \pm 3 \mathrm{~g} / \mathrm{kg}$ and $7.35 \pm 0.1$, respectively.

The seed microflora used for the hydrogenic reactor inoculation was a mixture of a livestock manure and a digestate produced in a labora-

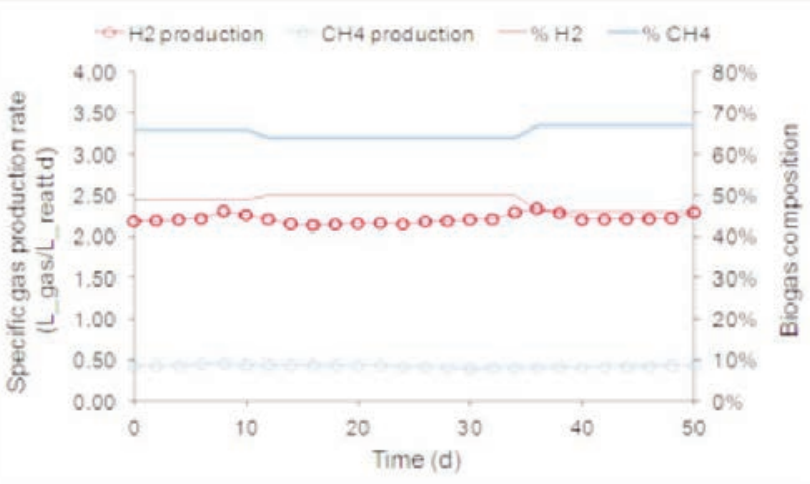

Figure 2. Specific volumetric gas production and composition in the twostage reactors tory-scale thermophilic reactor, fed with glucose and fruit wastes. Methanogenic reactors were inoculated directly with livestock manure, provided directly by the farm where plant is installed.

\section{Results and discussion}

\section{System start-up}

Before the start up, the inocula were briefly deaerated with $\mathrm{N}_{2}$ gas at a flowrate of $100 \mathrm{~mL} / \mathrm{min}$ to establish the anaerobic conditions favorable to the microflora development and activity. Then the inocula within the reactors were acclimatized for 15 days to thermophilic temperature $\left(55{ }^{\circ} \mathrm{C}\right)$, subjected to a gently stirring. During this time, the first stage was directly fed with the feeding mixture described in section 2.3 , and its effluent was simultaneously but partially added to the methanogenic reactors. Indeed, the methanogenic bacteria have slower growth rates and are easier to be subjected to inhibitions, such as by organic shock load, thus the organic load to the second stage was progressively increased during the start-up, until a biogas with methane percentage of $50 \pm 5 \%$ was achieved. After 15-20 days, when stable biohydrogen production (H2 content in biogas $40 \pm 5 \%$ ) from the first stage was reached, the hydrogenicdigestate was fully fed to the second reactors, achieving a fully integrated operation of the twophase AD process.

\section{Two-stage plant performances}

The process was continuously operated for more than one month with stable production both in the first and the second stage (Fig. 2). The specific volumetric production rate of hydrogen resulted in $2.1 \pm$ $0.2 \mathrm{Nm}^{3}{ }_{\mathrm{H} 2} / \mathrm{m}^{3}$ reactor $\mathrm{d}$ with a corresponding yield of $99 \pm 10 \mathrm{Ndm}{ }^{3}{ }_{\mathrm{H}} / \mathrm{kg}_{\mathrm{VS}}$ (Tab. 1), which is well in the range of other studies on highly degradable feedstock. The biogas produced by the first stage was in average composed by $48 \%$ hydrogen without any methane detected, showing that favorable conditions were created by the short HRT and the relative acidity of the fermentation broth. Indeed, the average $\mathrm{pH}$ of the hydrogenicstage $(5.78 \pm 0.10)$ resulted closely stable around the optimum for hydrogen production without chemicals addiction for $\mathrm{pH}$ adjustments, which is quite relevant for practical implementation of the process.

Methane production from the second stage was approximately 0.5 $\mathrm{Nm}^{3} \mathrm{CH} 4 / \mathrm{m}^{3}$ reactor $\bullet$, with a methane concentration in the biogas of $68 \%$ $\mathrm{v} / \mathrm{v}$, quite higher than typically reported for similar digestion processes.

Important reductions of the TS, VS and COD contents of the feeding mixtures were noted, with COD reduction after the first stage and after the overall process amounting to $25 \%$ and $69 \%$, respectively. At the same time, the system produced a total energy yield of 10-11 MJ/kg with the hydrogen production weighting for nearly the $15 \%$ of the total energy produced by the system (Tab. 1).

\section{Conclusions}

A two-stage pilot-plant digester at farm scale was successfully run for 1 month, efficiently exploiting typical agricultural and livestock residues, available to the farm (65\% of the organic matter was removed every cycle). Noticeable hydrogen and methane yield were achieved, in particular if related to the overall short cycle time required by the process ( 20 days). This study also showed higher $\mathrm{CH} 4$ content in the biogas from the second stage $(\approx 70 \%)$ than the traditional $\mathrm{AD}$, that is advantageous for lowering the biogas upgrading cost. 
Table 1. Results overview of the experimental two-stage plant operations

\begin{tabular}{|c|c|c|}
\hline & $\begin{array}{l}\text { Hydrogenic } \\
\text { stage }\end{array}$ & $\begin{array}{l}\text { Methanogenic } \\
\text { stage }\end{array}$ \\
\hline \multicolumn{3}{|l|}{ Volumetric production rate } \\
\hline $\mathrm{Nm}^{3}{ }_{\mathrm{H} 2 \mathrm{CH} 4} / \mathrm{m}_{\text {reactor }}^{3} \mathrm{~d}$ & $2.2 \pm 0.2$ & $0.5 \pm 0.1$ \\
\hline Average content of $\mathrm{H}_{2} / \mathrm{CH}_{4}(\%)$ & $48 \pm 2$ & $67 \pm 1$ \\
\hline Biogas yield $\mathrm{dm}^{3}{ }_{\text {нгсн4 }} / \mathrm{kg}_{\mathrm{vs}}$ & $105 \pm 10$ & $290 \pm 30$ \\
\hline Energy yield $\mathrm{MJ} / \mathrm{kg}_{v s}$ & $1.2 \pm 0.1$ & $9.3 \pm 1.1$ \\
\hline
\end{tabular}

\section{References}

Gomes Antunes, J. M., Mikalsen, R., \&Roskilly, A. P. 2008. An investigation of hydrogen-fuelled HCCI engine performance and operation. Int. J. Hydr. En., 33, 5823-5828.

Akansu, S. 0., Dulger, Z., Kahranman, N., \&Veziroglu, N. T. 2004. Internal combustion nginesfueled by natural gas-hydrogen mix- tures. Int. J. Hydr. En., 29, 1527-1539.

Ma, F., Ding, S., Wang, Y., Wang, M., Jiang, L., Naeve, N., \& Zhao, S. 2009. Performance and Emission Characteristics of a SI HydrogenEnriched Compressed Natural Gas Engine Under Various Operating Conditions Including Idle Conditions. Energy \&Fuels, 23, 2113-3118.

Cavinato, C., Bolzonella, D., Fatone, F., Cecchi, F., \& Pavan, P. 2011. Optimization of two-phase thermophilic anaerobic digestion of biowaste for hydrogen and methane production through reject water recirculation. Bioresource Technology, 102, 8605-8611.

Lee, Y. W., \& Chung, J. 2010. Bioproduction of hydrogen from food waste by pilot-scale combined hydrogen/methane fermentation. Int. J. Hydr. En., 35, 11746-11755.

Ueno, Y., Fukui, H., \&Goto, M. 2007. Operation of a Two-Stage Fermentation Process Producing Hydrogen and Methane from Organic Waste. Env. Sc. Techn., 41, 1413-1419.

Wang, X., \& Zhao, Y. C. 2009. A bench scale study of fermentative hydrogen and methane production from food waste in integrated twostage process. Int. J. Hydr. En., 34, 245-254.

Liu, D., Zeng, R. J., \&Angelidaki, I. 2006. Hydrogen and methane production from household solid waste in the two-stage fermentation process. Water Research, 40, 2230-2236. 